Supporting Information

\title{
Performance enhancement of reactive dividing-wall column via vapor recompression heat pump
}

Shenyao Feng, Xinyu Lyu, Qing Ye*, Hui Xia, Rui Li and Xiaomeng Suo

Jiangsu Key Laboratory of Advanced Catalytic Materials and Technology, School of

Petrochemical Engineering, Changzhou University, Changzhou, Jiangsu 213164,

China

\section{Author Information}

* Corresponding author. Tel.: +86 519 86330355. Fax: +86 51986330355 .

E-mail address: huagonglou508@126.com.

Table S1. Binary parameters for the UNIQUAC activity coefficient model

\begin{tabular}{llllll}
\hline Component $\mathrm{i}$ & PROOH & PROOH & PROOH & PROAC & $\mathrm{H}_{2} \mathrm{O}$ \\
Component $\mathrm{j}$ & PROAC & $\mathrm{H}_{2} \mathrm{O}$ & PROPRO & $\mathrm{H}_{2} \mathrm{O}$ & PROPRO \\
\hline $\mathrm{A}_{\mathrm{ij}}$ & 0 & 1.7668 & 0 & 0 & 2.1927 \\
$\mathrm{~A}_{\mathrm{ji}}$ & 0 & -2.333 & 0 & 0 & 6.7432 \\
$\mathrm{~B}_{\mathrm{ij}}$ & -100.425 & -651.246 & 131.27 & -295.53 & -887.597 \\
$\mathrm{~B}_{\mathrm{ji}}$ & 171.2559 & 600.4906 & -212.48 & 140.02 & -3266.07 \\
\hline
\end{tabular}

Appendix S1. Calculation method

1. TAC

TAC is expressed as:

$$
T A C=\frac{T C C}{P P}+T O C
$$


Where $P P$ represents the payback period.

$\mathrm{TCC}$ is given by:

$$
T C C=C_{c v}+C_{p l}+C_{h e}+C_{c o m p}
$$

TOC is given by:

$$
T O C=C_{s t}+C_{c w}+C_{e c}
$$

The column vessel cost $\left(C_{c v}\right)$ and the plate cost $\left(C_{p l}\right)$ are:

$$
\begin{gathered}
C_{c v}=\left(\frac{M \& S}{280}\right) \times 937.636 \times D^{1.066} \times H^{0.802} \times\left(2.18+3.67 \times c_{p}\right) \\
C_{p l}=\left(\frac{M \& S}{280}\right) \times 97.243 \times D^{1.55} \times H \times\left(1.0+1.7 \times c_{t}\right)
\end{gathered}
$$

Where $D(\mathrm{~m})$ represents the column diameter, $H(\mathrm{~m})$ represents the column height. Refer to Shi et al.'s ${ }^{1}$ research, the value of M\&S is set as 1536.5 in this paper. In equation (4), $c_{p}=1.00$ when the column pressure is less than $3.4 \mathrm{~atm}$. In equation (5), $c_{t}$ is 0 in a sieve tray, and 1.8 in a bubble-cap tray. It is assumed that the column vessel cost and the plate cost of the RDWC are 1.2 times those of the traditional distillation column. ${ }^{2}$

The heat transfer area $(A)$ is:

$$
A=\frac{Q}{U \cdot \Delta T}
$$

Where $Q(\mathrm{~kW})$ represents the heat duty, $\Delta T(\mathrm{~K})$ represents the temperature driving force, and $U$ represents the overall heat-transfer coefficients, which is 0.852 and $0.582 \mathrm{~kW} /\left(\mathrm{m}^{2} \cdot \mathrm{K}\right)$ in the condenser and reboiler respectively.

The heat exchanger cost $\left(C_{h e}\right)$ is:

$$
C_{h e}=\left(\frac{M \& S}{280}\right) \times 474.668 \times A^{0.65} \times\left[2.29+3.75 \times\left(C_{t}+C_{p}\right)\right]
$$

Where $C_{t}$ is equaled 1.35 in kettle reboiler, and 0.8 in fixed tube-sheet heat 
exchangers. $C_{p}$ is 0 when the pressure is under $10.2 \mathrm{~atm}$.

The compressor cost $\left(C_{\text {comp }}\right)$ is:

$$
C_{\text {comp }}=\left(\frac{M \& S}{280}\right) \times 1609.425 \times\left(\frac{h_{p}}{0.8}\right)^{0.82}
$$

Where $h_{p}(\mathrm{~kW})$ represents the input horsepower of the compressor.

The steam cost $\left(C_{s t}\right)$ is:

$$
C_{s t}=C_{s} \times Q_{R} \times 8000 \times 3600
$$

Where $Q_{R}(\mathrm{~kW})$ represents the reboiler duty, and $C_{S}(\$ / \mathrm{KJ})$ represents the steam cost. According to Luyben's paper ${ }^{3}, C_{s}$ is equaled $\$ 7.72$ per GJ in low-pressure steam (433K), $\$ 8.22$ per GJ in medium-pressure steam $(457 \mathrm{~K})$, and $\$ 9.88$ per GJ in high-pressure steam $(527 \mathrm{~K})$.

The cooling water cost $\left(C_{c w}\right)$ is:

$$
C_{c w}=C_{w} \times\left(\frac{Q_{C}}{\Delta T_{W} \times C_{p} \times 1000}\right) \times 8000 \times 3600
$$

Where $C_{w}(=0.03 \$ / \mathrm{kg})$ is the cooling water price, $Q_{C}(\mathrm{~kW})$ denotes the condenser duty, $\Delta T_{W}(\mathrm{~K})$ is the differential temperature, and $C_{p}[=4.183 \mathrm{~kJ} /(\mathrm{kg} \cdot \mathrm{K})]$ is the specific heat of water.

The electricity cost $\left(C_{e c}\right)$ is:

$$
C_{e c}=\frac{W_{\text {comp }} \times C_{e}}{\eta_{m} \times \eta_{c}} \times 8000
$$

Where $W_{\text {comp }}(\mathrm{kW})$ represents the output work of compressor, $C_{e}[=0.084$ $\$ /(\mathrm{kW} \cdot \mathrm{h})]$ is the price of electricity, $\eta_{m}(=0.6)$ is the motor efficiency, and $\eta_{c}(=0.8)$ is the compressor efficiency.

\section{Thermodynamic efficiency}

Thermodynamic efficiencies can be calculated using the laws of thermodynamics ${ }^{4}$, listed as follows:

According to the first law of thermodynamics: 


$$
\sum_{\substack{\text { out of } \\ \text { system }}}\left(n h+Q+W_{s}\right)-\sum_{\substack{\text { into } \\ \text { system }}}\left(n h+Q+W_{s}\right)=0
$$

According to the second law of thermodynamics:

$$
\sum_{\substack{\text { out of } \\ \text { system }}}\left(n s+\frac{Q}{T_{s}}\right)-\sum_{\substack{\text { into } \\ \text { system }}}\left(n s+\frac{Q}{T_{s}}\right)=\Delta S_{i r r}
$$

Effective energy balance considering heat and work exchanges:

$$
\sum_{\substack{\text { out of } \\ \text { system }}}\left(n b+Q\left(1-\frac{T_{0}}{T_{s}}\right)+W_{s}\right)-\sum_{\substack{\text { into } \\ \text { system }}}\left(n b+Q\left(1-\frac{T_{0}}{T_{s}}\right)+W_{s}\right)=L W
$$

Where $b=h-T_{0} S$, and $L W=T_{0} \Delta S_{\text {irr }}$ represents the lost work in the system. Minimum work of separation $\left(W_{\min }\right)$ is:

$$
W_{\min }=\sum_{\substack{\text { out of } \\
\text { system }}}(n b)-\sum_{\begin{array}{c}
\text { into } \\
\text { system }
\end{array}}(n b)
$$

Second law efficiency $(\eta)$ is calculated by:

$$
\eta=\frac{W_{\min }}{L W+W_{\min }}
$$

\section{3. $\mathrm{CO}_{2}$ emissions}

According to Gadalla et al.'s research ${ }^{5}, \mathrm{CO}_{2}$ is produced by burning a mixture of fuel and air based on the stoichiometric equation below:

$$
\mathrm{C}_{x} \mathrm{H}_{y}+\left(x+\frac{y}{4}\right) \mathrm{O}_{2} \rightarrow x \mathrm{CO}_{2}+\frac{y}{2} \mathrm{H}_{2} \mathrm{O}
$$

Where $\mathrm{x}$ and $\mathrm{y}$ represents the number of carbon and hydrogen atoms respectively.

$\mathrm{CO}_{2}$ emissions $\left(\left[\mathrm{CO}_{2}\right]_{\text {Emiss }}\right)$ are related to the heat of the combusted fuel $\left(Q_{\text {Fuel }}\right)$ in a heating system: 


$$
\left[\mathrm{CO}_{2}\right]_{\text {Emiss }}=\left(\frac{Q_{\text {Fuel }}}{N H V}\right)\left(\frac{C \%}{100}\right) \alpha
$$

Where $\alpha(=3.67)$ is molar mass proportion of $\mathrm{CO}_{2}$ and $\mathrm{C}$, while NHV $(\mathrm{kJ} / \mathrm{kg})$ denotes the net thermal value of fuels with the carbon content $(C \%)$. The NHV is set to $22,000 \mathrm{~kJ} / \mathrm{kg}$ and $C \%$ of the coal is set to 0.68 in this paper ${ }^{4}$.

In the boiler, the stream is produced by burning the fuel. The flame temperature in the boiler is lower than that in a furnace because the heat of burning is immediately removed to the steam. The quantity of the combusted fuel could be calculated from equation (19):

$$
Q_{\text {Fuel }}=\frac{Q_{\text {Proc }}}{\lambda_{\text {Proc }}}\left(h_{\text {Proc }}-419\right) \frac{T_{F T B}-T_{o}}{T_{F T B}-T_{\text {stack }}}
$$

Where $\lambda_{\text {Proc }}(\mathrm{kJ} / \mathrm{kg})$ is the latent heat, $h_{\text {Proc }}(\mathrm{kJ} / \mathrm{kg})$ is the enthalpy of steam, $T_{F T B}\left({ }^{\circ} \mathrm{C}\right)$ is the flame temperature, $T_{\text {stack }}\left({ }^{\circ} \mathrm{C}\right)$ is the stack temperature, and $T_{o}\left({ }^{\circ} \mathrm{C}\right)$ is the ambient temperature. The theoretical flame temperature is set to $1800^{\circ} \mathrm{C}$, and the stack temperature is set to $160^{\circ} \mathrm{C}$ in this paper ${ }^{6}$.

\section{References}

(1) Shi, L.; Huang, K.; Wang, S.-J.; Yu, J.; Yuan, Y.; Chen, H.; Wong, D. S. H. Application of Vapor Recompression to Heterogeneous Azeotropic Dividing-Wall Distillation Columns. Ind. Eng. Chem. Res. 2015, 54 (46), $11592-$ 11609.

(2) Dejanović, I.; Matijašević, L.; Halvorsen, I. J.; Skogestad, S.; Jansen, H.; Kaibel, B.; Olujić, Ž. Designing four-product dividing wall columns for separation of a multicomponent aromatics mixture. Chem. Eng. Res. Des. 2011, 89 (8), 11551167.

(3) Luyben, W. L. Design and control of the ethyl benzene process. AIChE J. 2011, 57 (3), 655-670.

(4) Seader, J. D.; Henley, E. J.; Roper, D. K. Separation Process Principles, 3rd ed.; John Wiley \& Sons, Inc., 2010.

(5) Gadalla, M. A.; Žarko Olujić; Jansens, P. J.; Jobson, M.; Smith, R. Reducing $\mathrm{CO} 2$ Emissions and Energy Consumption of Heat-Integrated Distillation Systems. Environ. Sci. Technol. 2005, 39 (17), 6860-6870.

(6) Jantes-Jaramillo, D.; Segovia-Hernández, J. G.; Hernández, S. Reduction of Energy Consumption and Greenhouse Gas Emissions in a Plant for the 
Separation of Amines. Chem. Eng. Technol. 2008, 31 (10), 1462-1469. 